\title{
TESTIMONIOS HISTÓRICO-ARTÍSTICOS DE FRAY DIEGO JOSÉ DE CÁDIZ EN MÁLAGA
}

\section{HISTORICAL-ARTISTIC EVIDENCES OF FRAY DIEGO JOSÉ DE CÁDIZ IN MÁLAGA}

\author{
Iluminada Rodríguez Morgado (Universidad de Málaga, Universidad de Sevilla) \\ irodriguezmorgado@gmail.com
}

Recibido: 15 julio 2021 / Aceptado: 15 septiembre 2021

\begin{abstract}
Resumen: El presente artículo aspira a ser un punto de referencia para el análisis de la presencia de fray Diego José de Cádiz en Málaga, que se testimonia gracias al patrimonio histórico, literario y artístico legado en cada uno de los sitios que visitó a lo largo de su vida, efectuando predicaciones y misiones. De este modo, nos centraremos en la capital de la provincia, con especial atención a su labor apostólica manifiesta en la huella patrimonial albergada en la catedral de Málaga y la iglesia de la Divina Pastora y Santa Teresa de Jesús del popular barrio de Capuchinos. De fray Diego de Cádiz se destaca la tenaz propaganda en torno a la advocación de la Divina Pastora, que lo llevó a ser llamado «apóstol de Andalucía», y que en Málaga se manifiesta a través de la fundación de la congregación de la Divina Pastora. Su cercanía con Ronda y la devoción que tenía hacia la Virgen de la Paz de dicha ciudad, benefició múltiples visitas a la capital, lo que ocasionó un legado artístico e iconográfico particular. Muy valorado por la religiosidad popular, su presencia sigue referenciándose en cada una de las representaciones artísticas del beato, a vertebrar mediante el uso de relicarios y la conservación de su iconografía.
\end{abstract}

Palabras clave: fray Diego José de Cádiz, Málaga, Divina Pastora, siglo XVIII, representaciones artísticas.

\begin{abstract}
This article aspires to be a point of reference for the analysis of the presence of fray Diego José de Cádiz in the capital of Málaga, which is witnessed thanks to the historical, literary and artistic heritage left in each of the sites that he visited throughout of his life, doing preaching and missions. In this way, we will focus on the city of Málaga, with special attention to its apostolic work manifested in the patrimonial footprint housed in the cathedral of Málaga and the church of Divina Pastora and Santa Teresa de Jesús from the popular neighborhood of Capuchinos. Fray Diego stands out for the tenacious dissemination of veneration to the invocation of the Divina Pastora, since them called "preacher of Andalusia", and in Málaga is
\end{abstract}


manifested through the foundation of the congregation of the Divina Pastora. His proximity to Ronda and the devotion he had towards the Virgen de la Paz in this city, benefited multiple visits to the capital, which led to a particular artistic and iconographic legacy. He was highly valued by popular religiosity, his presence continues to be referenced in each of the artistic representations of the Beatus that today remember him, structured in the use of reliquaries and preservation of his iconography.

Keywords: Fray Diego José de Cádiz, Málaga, Divina Pastora, 18th century, artistic representations.

Cómo citar este artículo:

Rodríguez Morgado, I. (2021). Testimonios histórico-artísticos de fray Diego José de Cádiz en Málaga. Revista Eviterna 10, 169-183 /

DOI: https://doi.org/10.24310/Eviternare.vi10.13162

\section{Introducción}

Tal y como se manifiesta en los diferentes documentos hagiográficos e históricos en torno a la figura del beato capuchino, a finales del siglo XVIII, fray Diego José de Cádiz destacó como predicador en las conocidas misiones populares. En ellas practicaría una labor oratoria itinerante que lo llevaría a visitar diferentes puntos de la geografía española, caso de Málaga. Es allí donde arraigará su pensamiento y principal devocionario e ideología, con la consiguiente proliferación de iconografías alrededor de su figura. De esta manera se facilitó su culto como beato, tras un arduo proceso que culminó en 1894, nueve décadas después de su fallecimiento. Su incesante actividad por toda la Península Ibérica, y, en este caso, por la provincia malagueña, es fundamental para comprender dicha remembranza, y así podremos analizar las manifestaciones histórico-artísticas efectuadas, motivos y vicisitudes principales, con objeto de reflejar la importancia de fray Diego en la capital malagueña, cuestión que perdura hasta nuestros días.

\section{Fray Diego de Cádiz: valedor de la pugna contra las luces}

Si bien este apartado no pretende eximir al grupo de ilustrados que tuvieron creencias religiosas, justo es decir que personajes como fray Diego protagonizaron una férrea lucha contra los preceptos que la mayoría de los miembros ilustrados defendían, ya que la separación de fe y razón suponía una subordinación de la Iglesia a una nueva forma de pensamiento (Ramírez González, 2004, pp. 102-105 \&t Durán López, 2014, p. 52). Algo que, sin duda, no fue cuestión que agradara a nuestro capuchino, tan implicado en promulgar la ortodoxia católica (Menéndez Pelayo, 1951, p. 1256). 
Ciertamente, no es extraño pensar que el beato Diego pudo ser un personaje afín a una ideología que, para muchos, estaba caduca y obsoleta, pero justo es decir que su figura fue singular debido a su peculiar forma de comunicar, transmitiendo las enseñanzas contenidas en las Sagradas Escrituras desde una perspectiva personal interesante y atractiva. Sus actividades y singularidades, en definitiva, influirán en la sociedad de su época, de manera que serán muchos los que se presten a escucharle, convirtiéndose en seguidores, empero, de igual modo, serán cuantiosos sus detractores. Esta estela será tenida en cuenta siglos después, llegando a ser beatificado y bautizado como el «apóstol de Andalucía ${ }^{1}$ », apodo recibido a tenor de su labor apostólica y difusora del culto a distintas advocaciones, caso de la Divina Pastora, la Santísima Trinidad y el culto a la Eucaristía.

Con todo, podemos adentrarnos en su modus operandi. Es en 1756, a la temprana edad de 13 años, cuando anhela profesar su fe, por lo que, después de realizar un examen de gramática un año después, inició el hábito en Sevilla (Serafín de Ardales, pp. 5-17). Finalmente, el 31 de marzo de 1759 profesó con el nombre de Diego José de Cádiz en el convento de Santa Justa y Rufina de los capuchinos hispalenses (Igualada, p. 8). A partir de este momento, su formación teológica propició que comenzara a realizar predicaciones, con Estepona como primer destino. Su éxito fue tal que el provincial capuchino de la orden decidió enviarlo a Ceuta en la cuaresma de 1773 (Gómez Barceló, 1995, p. 495). Su notoriedad ocasionó que hiciera la primera misión en Málaga, aspecto que relata el propio beato en la correspondencia con el padre González, su director espiritual: «Pasé después a Málaga donde había algún rumor [de sus óptimos resultados en Ceuta], y me instaron hiciese aquí misión; a que respondí la haría si la pedía el Ilmo. o su Gobernador. Volvime a Ubrique y fue el aviso para que viniese prontamente a dicho fin» (Valencina, 1902, p. 324). Así, nos encontramos ante el germen de su doctrina, la cual se valió de estudios sobre gramática. Estos se proyectaron en los infinitos sermones que escribió y que utilizaba en sus visitas a lo largo de la geografía española, y todos contemplan una estructura base, repetida en cada una de las muestras que actualmente conservamos.

Siempre inauguraba su labor con el rezo del rosario e incluía distintos cánticos y oraciones en torno a María de Nazareth, san José, el Santísimo Sacramento y la Trinidad, principales protagonistas de su extenso devocionario. Los enclaves escogidos estaban bien situados y permitían aglomeraciones, ya que eran muchos los congregados interesados. En ocasiones, el aforo de los inmuebles religiosos era insuficiente, lo que causaba que se desplazara a la plaza principal del lugar en cuestión.

El contenido del sermón variaba según las exigencias del sitio al que visitaba, por lo que existían particularidades que ayudan a comprender la personalidad del beato. Todo ello se complementaba con altas dosis de teatralidad, ya que se mostraba agitado y se acompañaba del estandarte de la Divina Pastora y de un crucifijo con el que mantenía conversaciones en la mayoría de las ocasiones. De este modo, fray Diego pretendía demostrar su acercamiento a

\footnotetext{
${ }^{1}$ Este sobrenombre fue empleado anteriormente por distintos autores para referirse a otros personajes a los que se atribuían las mismas cualidades, caso de san Juan de Ávila en el siglo XVI.
} 
Dios, quien, según su criterio, lo había escogido como mediador y vehículo conducente a la expiación de pecados. Conviene referir que su fama condicionó la gran actividad ejercida, sobre todo si atendemos a la infinitud de emplazamientos que visitó ( $y$ algunos de ellos en reiteradas ocasiones). Ello mermó la capacidad creativa e ingeniosa del beato, que a veces predicaba sermones poco innovadores, a los que añadía alguna que otra referencia particular y autóctona (Durán, 2014). En este sentido, cabe resaltar que su modelo, con alteraciones, es muy similar al llevado a cabo por el resto de religiosos contemporáneos a su época:

Un pequeño grupo de sacerdotes [...] acudía varios días a una localidad [...] Allí llevaban a cabo un acelerado programa de activismo espiritual cuyo centro inexcusable eran varios vibrantes sermones, pero que iban acompañados de procesiones, confesiones y comuniones masivas, mortificación de la carne mediante ayunos o disciplinas, elucidaciones de la doctrina a escolares e iletrados, actos de devoción a los santos o vírgenes de culto local, reuniones con autoridades, párrocos y fuerzas vivas. Durante esos días los misioneros instigaban denodadamente un estado de emergencia espiritual y moralidad extrema, arreglando las desavenencias entre vecinos, casando a las parejas amancebadas, cerrando teatros y lugares de vicio, convirtiendo o reconviniendo a notorios impíos... (Durán, 2014, p. 54).

A este respecto, apuntamos a la lucha de Diego de Cádiz contra el teatro en la provincia de Málaga, ya que era común que las actividades teatrales fuesen suspendidas tras sus visitas. Del mismo modo, la propagación de la devoción de la Divina Pastora y sus acusantes avisos moralizantes serán una constante, como veremos en el siguiente apartado. Asimismo, todo lo comentado se incrementará gracias al fervor popular, que atribuirá milagros, sanaciones y todo tipo de prodigios a su persona.

Todo ello nos lleva a comprender la proliferación de una iconografía particular en torno al beato y sus devociones, así como el deseo de conservar en la provincia reliquias, misivas y epístolas escritas de su puño y letra, y que hoy día son custodiadas e igualmente valoradas.

\section{Vestigios histórico-artísticos en torno a fray Diego José de Cádiz: Málaga capital}

«Algunas veces que el pueblo lo vitoreaba diciendo: viva el Padre Cádiz les persuadía que dixesen: viva la Santísima Trinidad. Así sucedió en la Plaza mayor de Málaga [...]» (Ardales, 1811, p. 75).

Las palabras de Serafín de Ardales nos acercan a la personalidad del beato, siempre dispuesto a expandir la devoción del dogma central de la Iglesia Católica, lo que ocasionó la inclusión de altares callejeros en torno a la Santísima Trinidad por la provincia de Málaga (Ubrique, 1926, Tomo II, p. 152). De la misma forma, observamos la popularidad que a su personaje otorgaban las grandes masas de personas que acudían a su encuentro cada vez que visitaba la capital malagueña, una de sus moradas recurrentes.

La primera misión que fray Diego practicó en Málaga fue en 1773, y Serafín de Ardales recoge que fue «[...] a petición de su Nobilísimo Ayuntamiento, é Ilustrísimo Obispo, siempre con el fruto que acompañaba» (p. 19). En ella, predicó de Dogmas en la catedral y 
estuvo tres días haciendo confesiones. Sus habilidades oratorias fueron tales que, el propio fray Diego, narraba asombrado lo acontecido en la ciudad. Había pensado ofrecer un sermón que olvidó al subirse al púlpito, y, ante ello, apesadumbrado, tuvo que desarrollar un tema distinto (Ardales, 1911, pp. 53-54; Valencina, 1902, pp. 324-325). Para su fortuna, la respuesta de la ciudad fue positiva conforme a sus propósitos y propiciaría su venida en múltiples ocasiones, satisfaciendo así peticiones civiles y religiosas.

Fue en 1779 cuando se efectuó la segunda misión en la capital malagueña, donde el padre Juan Bautista de Ardales nos cuenta la necesidad de la presencia del beato por las pestes, siendo una de las misiones «más fuertes y aterradoras» (1949, p. 200). Tanta fue la asistencia que se vio obligado a predicar en una de sus apariciones fuera de la catedral'. Insólita fue la afirmación que salió de sus labios, ya que declaraba que, en cuestión de horas, se habían producido en Málaga veintidós mil pecados mortales. Sus palabras causaron desasosiego y ansias de expiación, por lo que muchos ciudadanos acudieron al calvario malacitano o se confinaron aterrorizados en sus viviendas, con objeto de realizar prácticas penitenciales (Ardales, 1949, p. 202).

A este respecto, interesantísima es la ilustración contenida en la obra biográfica La Divina Pastora y el Beato Diego José de Cádiz [Fig. 1]. En ella podemos observar la que seguramente fue la aparición en la capital fechada el 23 de febrero. El capuchino se encuentra sobre una estructura a modo de púlpito que lo enaltece frente a la muchedumbre que se agolpa para escuchar sus palabras. Fray Diego muestra una postura acusadora, extendiendo uno de sus brazos de manera agitada, y su rostro manifiesta la pronunciación de las duras palabras que dedicó a aquellas gentes. A su lado, se encuentra el estandarte de la Divina Pastora, que, como antes referíamos, siempre lo acompañaba en sus misiones. Al fondo, representada de forma muy reconocible, con una de las torres inacabada, se alza la catedral de Málaga, lo que nos permite contextualizar este momento. El beato aparece asimismo con las señas propias de su iconografía, esto es, con hábito capuchino y rostro alargado acompañado de una larga y prominente barba. Los personajes que le rodean pertenecen a todos los rangos sociales, algo destacable, puesto que el beato tenía relación con personalidades distinguidas y formaba parte de actos políticos asiduamente $e^{3}$.

La peste fue un tema candente por razones obvias en el siglo XVIII, generándose, a raíz de las rogativas y rezos que protagonizaba fray Diego, un patrimonio musical que conservamos en los fondos archivísticos de la catedral de Málaga. Varios poemas escritos por fray Diego fueron acompañados de melodías musicales, como la efectuada por Jorge Grofs para los textos que realizó el beato gaditano, titulada Canción devota y deprecatoria del R. P. Fr. Diego de Cádiz, 31 de agosto de 1854. También atesora otra adaptación anónima, Poesía

\footnotetext{
${ }^{2}$ Nos referimos a la primera de sus predicaciones en dicho año, el 23 de febrero. Luego, en el epistolario del propio fray Diego, en una carta del 12 de marzo de 1779, aclara que la última, fechada el 9 de marzo, tuvo lugar en el templo catedralicio.

3 Tanto es así, que intentó aconsejar espiritualmente a la reina María Luisa de Parma, y fue acusador y acusado en el tribunal de la Inquisición, siendo incluso exiliado durante un tiempo, cuestión que no mermó su labor apostólica.
} 
del Padre Fr. Diego José de Cádiz para implorar del Señor nos libre del contagio de la peste. A ello sumamos la creación del Himno a fray Diego José de Cádiz por Eduardo Ocón, segundo organista de la catedral en tiempos de su beatificación (Rodríguez de Tembleque, 2016, pp. 214-217). En las letras de estas piezas, en línea con lo expresado, se hace alusión a los castigos divinos por la infinitud de pecados, y la necesidad enmendar conductas después de una larga vida de vicios, que había conducido a los afectados a contraer enfermedades.

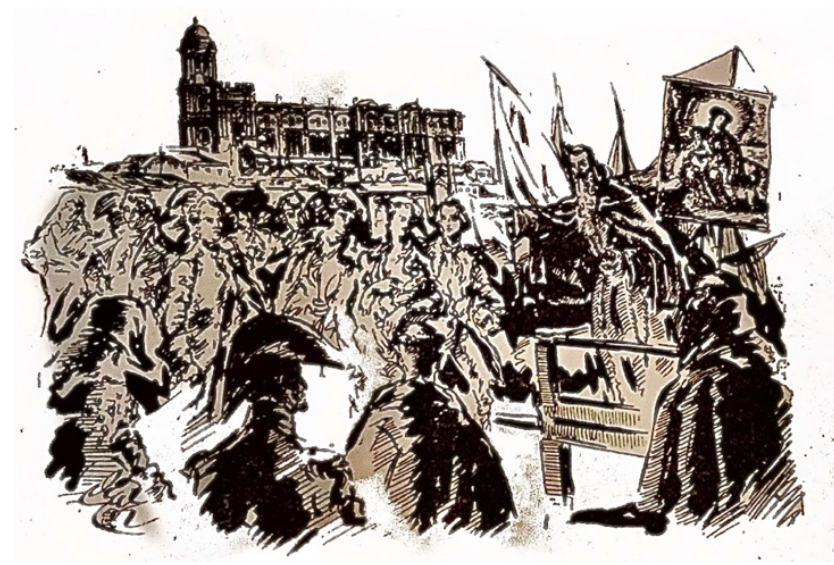

Fig. 1. Anónimo: Predicación de Fray Diego José de Cádiz en Málaga en 1779. Lámina extraída de J. B. de Ardales (1949). La Divina Pastora y el Beato Diego José de Cádiz. Sevilla: Imprenta de la Divina Pastora, p.

201.

Ronda, la ciudad del Tajo, fue el lugar de retiro espiritual y descanso del beato, sobre todo a raíz de 1786, cuando su deterioro físico hizo mermar sus viajes (Ramírez, 2004, p. 112). Sentía especial predilección por esta ciudad, cuestión vinculable a la devoción que siempre profesó por la Virgen de la Paz, hoy patrona de la ciudad de Ronda, en parte, gracias a su persistente labor. Esta se veía determinada por la expansión de su devoción y el aumento del patrimonio inmueble y mueble que rodeaba a la efigie mariana ${ }^{4}$. Tanto es así, que su ajuar ha aumentado a consecuencia de dádivas de otros devotos que continuaron la labor de Diego de Cádiz. Hoy día sus restos mortales descansan a los pies de dicha imagen, albergados en una urna de plata que siempre acompaña a la Virgen de la Paz, incluyendo procesiones o traslados.

Hecha esta aclaración, hemos de comentar la constante ida y venida del mismo a la capital por la cercanía con su residencia habitual, y que esta presencia condicionó en gran medida la religiosidad popular malacitana. Ejemplo de ello es el sermón de acción de gracias con los pobres enfermos que predicó en el barrio del Perchel malagueño para la hermandad de la Misericordia, en el templo de Santo Domingo de Guzmán (mayo de 1792). Pese a que la finalidad de este sermón era agradecer la ratificación como hermandad, exhortaba a los presentes a seguir practicando las obras de misericordia con los enfermos. La duración sobrepasó las cuatro horas, como acostumbraba, y a lo largo de sus líneas se perciben las ya

\footnotetext{
4 Para más información, importantísimas y relevantes son las publicaciones del profesor Sergio Ramírez González, relativas al ajuar de la Virgen de la Paz, de Ronda, la iconografía de su camarín y las diferentes obras artísticas albergadas en el inmueble que Diego de Cádiz visitó y cuidó hasta el fin de sus días (2003, 2004).
} 
comentadas alabanzas a la Santísima Trinidad y referencias a la Virgen María. A ello sumamos la inclusión de un saludo en su sermón, como marcaban los decretos del obispado de Málaga, en el que aclaraba un pasaje del catecismo (Rodríguez de Tembleque, 2014, p. 103). Como colofón a este amplio sermón, no encontramos mejor afirmación que la que hizo el propio fray Diego, y que nos aproxima a su ideario, relativo a la supresión de los teatros: «sabemos que las pasiones no se curan sino con la mortificación: la mala costumbre con los actos contrarios; y la ocasión próxima con el retiro y la fuga» (Cádiz, 1792, p. 47).

Este tipo de actos, tanto públicos como religiosos, eran comunes, aunque también fueron relevantes las visitas a conventos y suficientes las conversaciones privadas con aquellos que quisieron recibir sus consejos, lo que propició la difusión de supuestas sanaciones y milagros que al capuchino adjudicaban.

En definitiva, toda esta coyuntura facilitó que hoy la catedral de Málaga conserve varias piezas que actúan como remembranza del beato. Nos referimos a dos relicarios, uno de ellos portador de una de sus costillas, depositada en 1895 por el obispo Marcelo Spínola, un reclinatorio donde acostumbraba a orar en el templo mayor malacitano, además de un retrato emplazado en la capilla de San Julián.

El primer relicario, contenedor de la costilla del beato, es del siglo XIX, de plata fundida y adscrito al estilo rococó. Destaca la peana de madera troncopiramidal, con un astil de columnas que flanquean un ángel orante que despliega sus alas. La pieza se termina con un marco acristalado de tipo oval con decoración vegetal. El segundo de los relicarios, obra anónima malagueña y cuya cronología puede adscribirse al segundo tercio del siglo XIX, es de plata fundida y repujada. Participa del gusto neobarroco, con una base circular que alterna formas convexas y troncocónicas, y cuyo astil integra un nudo compuesto por grueso toro y forma acampanada invertida. Tanto la base como el astil se decoran con espejos y tornapuntas vegetales. La pieza finaliza con una forma troncocónica acristalada que alberga la reliquia, rematada de una cúpula con cruz [Fig. 2].
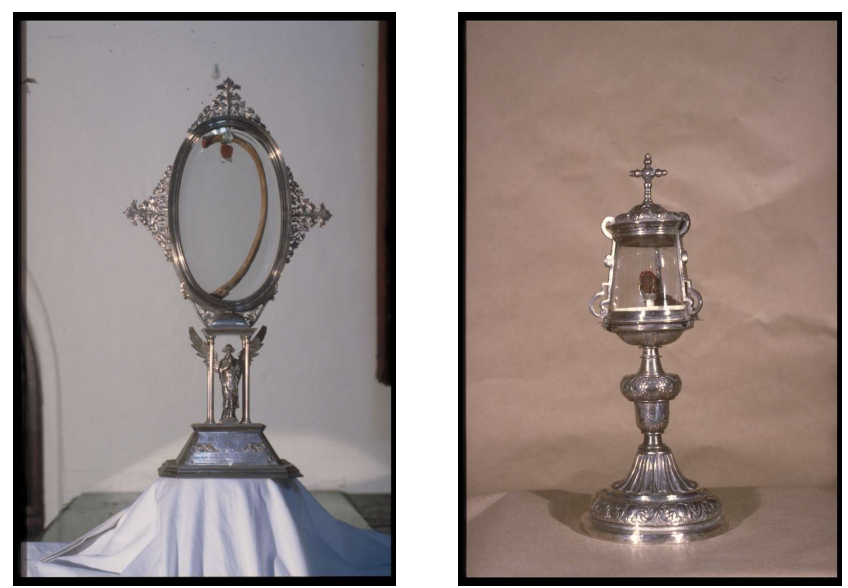

Fig. 2. Anónimo andaluz. Relicario del beato Diego de Cádiz, 1850-1899; y anónimo malagueño. Relicario del beato fray Diego de Cádiz, 1833-1865. Ambos, en la catedral de Málaga. Fotografías: Eduardo Nieto y José Miguel Morales Folguera. 
De la misma centuria es el retrato del beato [Fig. 3], vinculado a la escuela andaluza. Este óleo sobre lienzo representa al beato en avanzada edad, de medio cuerpo, vestido con el hábito capuchino, abrazando el crucifijo en un estado de meditación e introspección. Su rostro sigue los cánones establecidos por sus otros muchos retratos, con barba blanca alargada y mismos rasgos fisonómicos. El fondo descontextualizado se acompaña de una gama cromática negra y ocre, y recoge en la esquina superior izquierda un triángulo de la Santísima Trinidad que alumbra al capuchino, en un nuevo guiño a su consolidado devocionario.

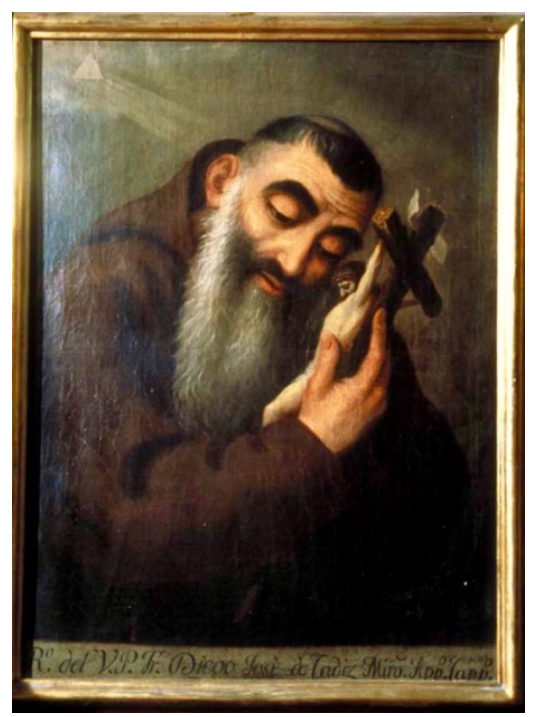

Fig. 3. Anónimo andaluz, Retrato de fray Diego de Cádiz, siglo XIX, catedral de Málaga. Fotografía de IAPH.

A este respecto, apuntamos que los artistas que recibieron el encargo de representar a fray Diego en los diferentes puntos peninsulares se sirvieron de referencias literarias, de nuevo, producidas por sus biógrafos, cuestión que facilitó la difusión de directrices retratísticas normalmente homogéneas, caso de las palabras del padre Serafín de Ardales (1811, pp. 226227):

Su fisonomía, o exterior figura fue, de estatura hasta los hombros de dos varas bien cumplidas: su corpulencia formada, y con proporcionadas carnes, con todos sus miembros iguales correspondientes y fuertes [...] correspondiendo su figura de la cara que tocaba más en aguileña, que en redonda, su pelo negro como azabache, hermosa y despejada frente, sin la nota de grande ni pequeña: las cejas muy pobladas y gruesas, cuyo entrecejo era muy limpio: sus ojos con lo azulado de lo blando, el tamaño y negro de las pupilas [...] la nariz recta, y delgada hasta su final: la boca ni grande ni pequeña [...] su barba muy poblada, algo crepa, y larga hasta como tres dedos cerca de la cintura, y las orejas bien formadas y situadas [...].

Igualmente, no fueron escasas las alusiones a su personalidad y dones, que también contribuyeron a la expresión de su rostro: «Su venerable presencia, amable carácter, dulce y humilde conversación, edificante conducta, perspicaz ingenio, su laboriosidad, erudición, y eficacia en la predicación, ya meditada, ya repentina, con admiración de los oyentes, hace preciosa y recomendable su memoria» (Ardales, 1811, p. 234). 
Y esta recomendada memoria no pasó desapercibida por los cercanos al convento capuchino malagueño, lugar donde fray Diego pasó largas temporadas, lo que favoreció su propósito de posibilitar la veneración de la advocación de la Madre del Buen Pastor, y que culminó con la institución de la congregación de la Divina Pastora de las Almas malacitana en el año $1771^{5}$. Su incesante labor pastoral ocasionó que llegara a redactar misivas mientras proseguía con las acciones piadosas en el convento, caso de una de las cartas hoy conservadas en el archivo de la congregación pastoreña. Su contenido es revelador porque muestra otra de las facetas de fray Diego, que es la de personaje influyente, valedor de decisiones. El asunto contenido en esta carta está marcado por la estrecha amistad creada a partir de sus estudios primarios en Grazalema con Diego José Benítez y Chacón, quien se presentó a las oposiciones a la plaza de canónigo magistral de la catedral de Málaga, convocadas en el año 1794. Como es bien sabido, la obtención de este cargo suponía que el afortunado fuese el canónigo que predicase en la catedral, beneficio eclesiástico valorable donde los haya. Fray Diego, que no estaba ajeno a estos asuntos, vio en su amigo Diego José el mejor postulante de los quince que se presentaron. La amistad, forjada desde temprana edad, se reforzó a raíz de las visitas a Osuna del beato, donde Benítez estuvo durante bastante tiempo. Así se lo hacía saber en la carta que conserva la congregación a Francisco de Loyo, quien fue canónigo de la catedral de Málaga, expresándole su deseo de que apoyase a Diego José en su candidatura, al ser, según su criterio, portador de infinitas virtudes:

Celebraría poderle informar de todas las apreciables circunstancias para que inclinase a su favor en los términos de caridad y justicia que exigen estos asuntos: su cristiana mansedumbre, genio pacifico, inocencia de costumbres, conducta arregladísima, erudición sobresaliente, notoria piedad, aplicación laboriosa a las tareas y ministerios de un verdadero eclesiástico [... $]^{6}$.

La interesantísima carta culmina con los beneficios de la Iglesia de Málaga al adquirir sus dones y el agradecimiento por tener en cuenta esta petición, necesaria para «el bien de las almas». Sin duda, fray Diego sabía emplear una prosa elocuente para alcanzar sus objetivos, que finalmente se vieron satisfechos. Las dotes de oratoria y teología de Diego José Benítez fueron ciertamente demostrados, puesto que una vez consiguió el puesto, sus sermones fueron conocidísimos por su brillantez, algo lógico si atendemos a que con la pronta edad de 28 años fue nombrado catedrático y rector de la universidad de Osuna.

En suma, esta sería una de las copiosas cartas que circularían por el convento, a tenor de las múltiples ocasiones en las que fray Diego se hospedaba y, celoso de sus quehaceres diarios, decidía proseguir con sus escritos y misivas. Al respecto, el padre Juan Estrada (1972, p. 13) reflexionaba acertadamente:

\footnotetext{
${ }^{5}$ Este hallazgo por Juan Cristóbal Jurado ha facilitado la certificación de fundación por parte del obispado de Málaga desde el año 2017, tras el estudio de una carta escrita por Diego de Cádiz donde confirma tales hechos, depositada en el Archivo de la Provincia Capuchina de Andalucía, leg. 19, Correspondencia del beato Diego José de Cádir: 1761-1784. Carta del 17 de septiembre de 1779.

${ }^{6}$ Archivo de la congregación de la Divina Pastora de Málaga (A.C.D.P.M.), Carta de Fr. Diego José de Cádiz a Juan Francisco de Loyo el 23 de mayo de 1795.
} 
El tiempo que permanecía en el convento debió ser de descanso para él. Pero esto solo a medias. Riadas de personas subían las cuestas de Capuchinos, sedientas de beber en las aguas limpias de su doctrina [...] todos quedaban edificados, observándole celebrar la santa misa, muchos se ponían bajo su dirección espiritual y recibían consejos.

También apunta al fervor que tenía a la actual imagen de la Divina Pastora malagueña y las acciones que practicaba en la iglesia: «Esta misma imagen de la Divina Pastora que hoy veneramos recibió sus más tiernas miradas; ante este antiguo sagrario pasó muchas horas de oración, y ante él, con gran humildad, leía las cartas que recibía de su director espiritual, el padre González» (Estrada, 1972, p. 14).

Todo ello puede ayudarnos a comprender la repercusión de fray Diego y, por ende, la veneración y difusión de su iconografía a lo largo de las estancias del convento. Destacamos la anónima pintura de Fray Diego junto a la Divina Pastora [Fig. 4]. En consonancia con la pintura dieciochesca contemporánea a su tiempo, la imagen de la Virgen aparece en el lado derecho de la composición, sentada y ataviada con manto azul y túnica blanca, acorde a los tonos inmaculistas. Los atributos bucólicos son recurrentes, tales como el pellico pastoril que está anudado a su cintura, y el sombrero de paja que se deposita sobre su cabeza, santificada e iluminada por una aureola. Acaricia una de las cinco ovejas que la rodean, mientras otra se alimenta de los tallos de flores que porta en su mano izquierda, simbolizando el rezo del rosario. El resto busca flores para ofrecérselas. Tras su brazo derecho se ubica un sencillo cayado, que complementa la iconografía tan difundida por fray Isidoro tras su encargo pictórico a Alonso Miguel de Tovar, pintor autor del prototipo a representar, y evidente inspiración del anónimo autor de este lienzo. En esta misma escena bucólica, en el lado izquierdo, se encuentra fray Diego, quien, de rodillas y vestido con hábito capuchino, medita contemplativo abrazando al crucifijo.

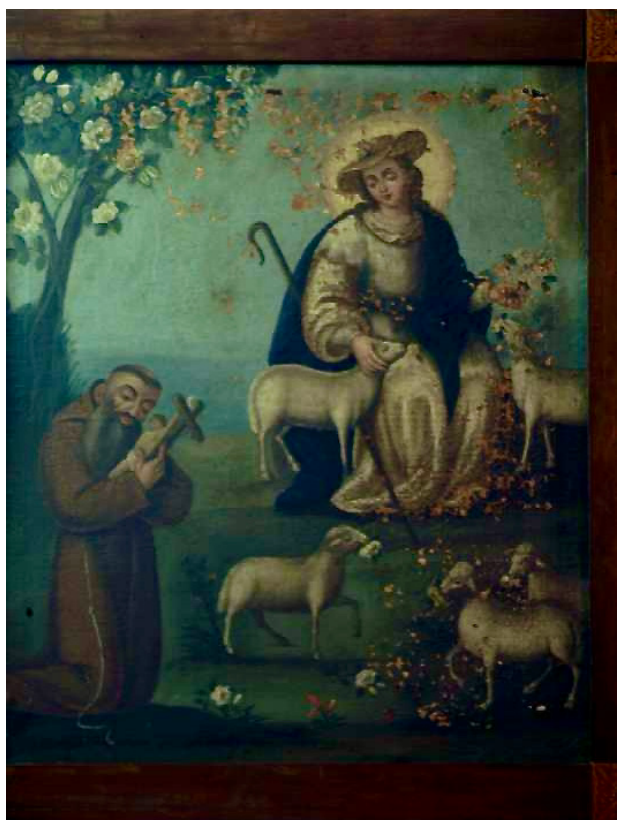

Fig. 4. Anónimo. La Divina Pastora y fray Diego José de Cádiz, siglo XVIII, convento de Santa Clara de Málaga. Fotografía de IAPH. 
Dadas las circunstancias, no es extraño apuntar que, en vida, fray Diego encabezó todo tipo de campañas, adquiriendo algunos privilegios, cuestiones que incrementarán el deseo de beatificarlo a lo largo del siglo XIX y de venerarlo hasta nuestros días. Es el caso de su incansable lucha en busca de la institución de la fiesta litúrgica de la Divina Pastora, alcanzando finalmente la de Madre del Buen Pastor. Redactó los textos encaminados a la causa, conseguida a los años, después de mucha insistencia y peticiones reales que no fueron atendidas. Pese a esto, no se desalentó, llegando así la aceptación papal, lo que hizo que cobrase fuerzas. Logró que en 1797 se entronizase la Divina Pastora del convento capuchino de Sevilla y, un año más tarde, obtuvo la ordenación expresa por parte de un decreto del definitorio provincial que estipulaba la colocación de un altar con la Divina Pastora en todo templo y convento capuchino. Por último, también se debe a fray Diego el nombramiento de la Divina Pastora como patrona de las misiones capuchinas (Sánchez López, 1996, p. 48).

Por todo, de un tiempo a esta parte la difusión de la veneración del beato Diego ha ocasionado la proliferación de obras artísticas que refrendan su importancia en Málaga capital. Es el caso del patrimonio que atesora la congregación, donde podemos encontrar un relicario del siglo XIX [Fig. 5], austero en ornamentación, de leves incisiones y con una forma circular ornada con rayos solares rectos donde se alberga la reliquia, rematada con una cruz. Esta se acompaña de documentación acreditativa de veracidad de la misma, clasificada como ex ossibus desde el 31 de mayo de 1981, firmada por fray Bernardinus a Senis, general postulador de los frailes menores capuchinos?.

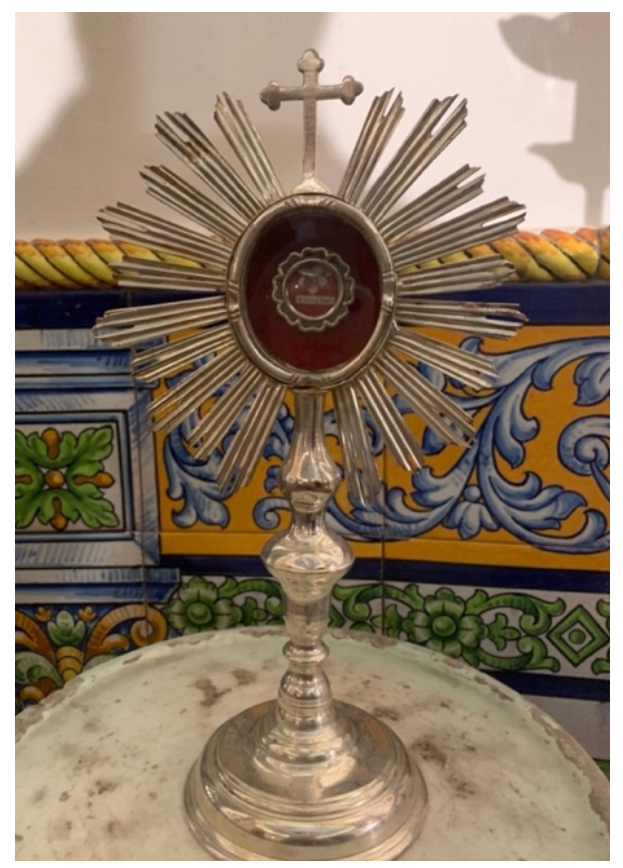

Fig. 5. Anónimo. Relicario de fray Diego de Cádiz, siglo XIX, iglesia de la Divina Pastora y Santa Teresa de Jesús de Málaga. Fotografía de la autora.

\footnotetext{
${ }^{7}$ A.C.D.P.M. Certificado de autenticidad de la reliquia de fray Diego José de Cádiz.
} 
También son varios los retratos pictóricos atesorados, aunque en estos se representa al fraile en un estado de oración muy similar al anteriormente comentado de la catedral de Málaga. A este respecto, cobra protagonismo el mosaico de azulejería realizado por el horno de Mensaque y Manuel Romero en 1976 [Fig. 6]. En él, la Divina Pastora aparece tal y como dispuso fray Isidoro, elevada sobre una peana de carrete malagueña. Por otro lado, el arco de medio punto, con decoración de motivos florales a modo de candelieri, presenta distintos medallones donde se albergan personalidades o atributos, siendo fray Diego de Cádiz quien toma protagonismo en la escena junto al creador de la advocación, fray Isidoro.

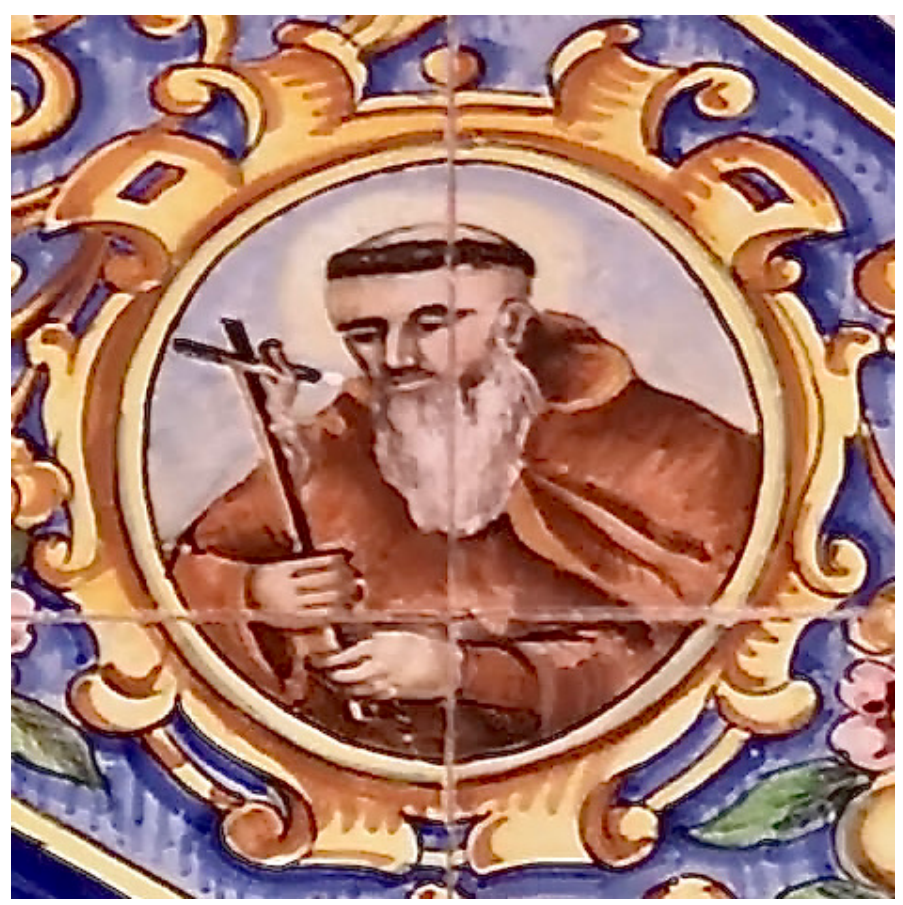

Fig. 6. Horno de Mensaque y Manuel Romero, Mosaico de azulejería de la Divina Pastora, detalle de Diego de Cádiz, 1976, iglesia de la Divina Pastora y Santa Teresa de Jesús de Málaga. Fotografía de la autora.

Destacamos la escultura del beato realizada para formar parte del trono de la Divina Pastora malagueña, obra de Domingo García Chahuán en 2013 [Fig. 7]. Esta se ubica en el lateral izquierdo del trono y forma parte de un conjunto iconográfico de los principales personajes vinculados a la congregación capuchinera, siendo todos estos representados de medio cuerpo y con los principales atributos que les caracterizan. Fray Diego, de expresión madura y espiritual, aparece surgiendo de una nube plateada, con el hábito capuchino y mostrando al público espectador el crucifijo.

Por último, estos asuntos no son ajenos a otras hermandades de nueva creación, caso de la hermandad del Dulce Nombre de Málaga, quien personifica en la gloria de palio de su titular dolorosa a la Divina Pastora malacitana, atribuida a José Montes de Oca (Sánchez López, 1996, p. 51) en una bucólica escena junto a fray Diego de Cádiz, que abraza al niño Jesús. La obra de José Palma es sin duda peculiar y significativa, ya que muestra la pervivencia del legado del beato en nuestra ciudad. 


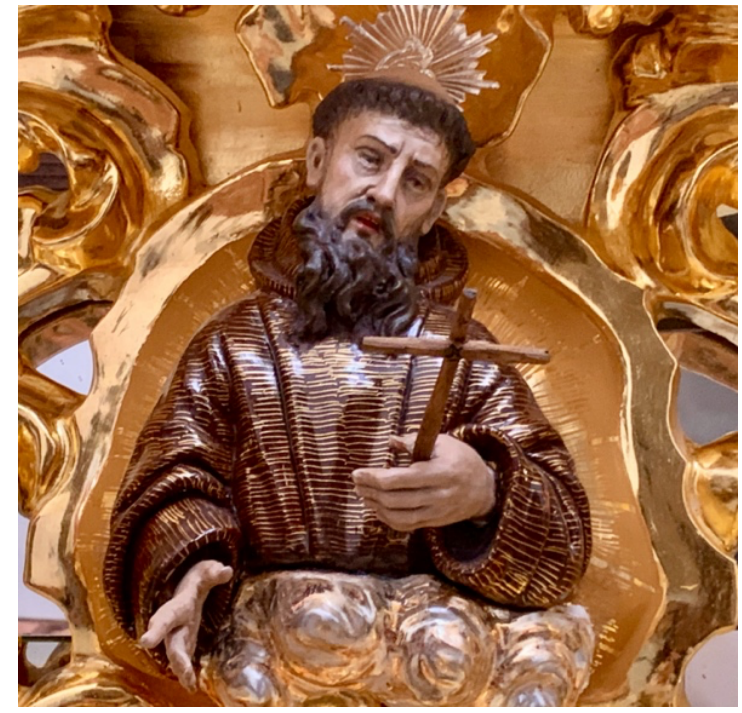

Fig. 7. Domingo García Chahuán. Beato Diego de Cádiz, perteneciente al trono de la Divina Pastora, 2013, iglesia de la Divina Pastora y Santa Teresa de Jesús de Málaga. Fotografía de la autora

\section{Conclusiones}

El estudio de la trascendencia y el valor de la presencia de fray Diego José de Cádiz en los diferentes puntos de la geografía peninsular, caso de Málaga, evidencia la importancia que tiene la religiosidad popular en la gestación de hitos histórico-artísticos que, finalmente, definen la identidad de un colectivo.

Un colectivo que transmite como legado cultural y popular la veneración de este tipo de personajes tan peculiares y significativos, lo que ocasiona la creación de diferentes obras artísticas que pueden ayudarnos a comprender un fenómeno histórico y su repercusión en próximos periodos cronológicos.

Así, este tipo de investigaciones permiten conocer y valorar el rico patrimonio en torno a la memoria de fray Diego José de Cádiz en la ciudad de Málaga. La difusión de piezas de artes decorativas significativas, caso de los relicarios, suscita una revalorización de las actividades artísticas encaminadas a la consecución de este tipo de objetos. Igualmente, la indagación a partir de la obra de arte y el análisis iconográfico de la misma establece conclusiones interesantes acerca del beato, su contexto y la particularidad intrínseca malagueña. Sin duda, todo ello propicia la futura creación de trabajos que versen sobre los vestigios histórico-artísticos y estudios culturales en torno a fray Diego de Cádiz en la provincia de Málaga.

En definitiva, la atención a la pervivencia de la memoria motiva la empatía y proximidad con los sucesos narrados y posibilita una mejor difusión de aquellos hechos que condicionan la configuración del patrimonio que hoy podemos visitar y estudiar, gracias a la cuidada labor bibliográfica de aquellos que quisieron rememorar acontecimientos significativos para el devenir de la sociedad, y que, como ya apuntábamos, determinan la actualidad más inmediata. 


\section{Referencias bibliográficas}

Ardales, J. B. de (1949). La Divina Pastora y el Beato Diego José de Cádiz. Sevilla: Imprenta de la Divina Pastora.

Ardales, S. de (1811). El misionero capuchino, compendio histórico de la vida del venerable siervo de Dios el M. R. P. Fr. Diego de Cádiz. San Fernando: Miguel Segovia.

Cádiz, D. J. de (1972). Excelencias de la misericordia para los pobres enfermos: sermón panegírico-histórico-moral, que es la solemne función que hicieron en la Iglesia del Convento del P. Sto. Domingo, Orden de Predicadores, la mañana del día 4 de Mayo de este presente año de 1792 los individuos de la nueva y V. Hermandad de la Misericordia con los pobres enfermos, sita en el barrio del Perchel de ... Málaga... Málaga: Luis de Carreras.

Durán López, F. (2014). Las artes de un predicador en guerra con las Luces: teoría y práctica de la oratoria sacra según el epistolario de Fray Diego José de Cádiz, Dicenda: Estudios de lengua y literatura españolas 32, 51-81. Recuperado de: https://revistas.ucm.es/index.php/DICE/article/download/47139/44197/

Estrada Castro, J. (1972). La Divina Pastora y el barrio de Capuchinos. Málaga.

Gómez Barceló, J. L. (1995), Presencia en Ceuta del Beato Diego José de Cádiz, Estudios Franciscanos 96, 495-516.

Igualada, C. de (1894). Vida del Beato P. Fr. Diego de Cádiz, religioso sacerdote de la Orden de M. Capuchinos de S. Francisco. Cádiz: Imprenta de la Revista Médica de Federico Joly.

Menéndez y Pelayo, M. (1951). Historia de los heterodoxos españoles. Madrid: Espasa-Calpe.

Ramírez González, S. (2002). Discurso iconográfico y simbolismo mariano del templo de la Virgen de la Paz. En I. Coloma Martín, M. T. Sauret Guerrero, B. Calderón Roca \& R. Luque Ramírez (Eds.), Correspondencia e integración de las artes: 14으 Congreso Nacional de Historia del Arte (pp. 405-424). Málaga: Universidad.

--- (2004). Fray Diego José de Cádiz y el ocaso de la predicación barroca: vestigios históricoartísticos en Ronda. En Peláez del Rosal, M. (Coord.). El Franciscanismo en Andalucía: Conferencias del IX Curso de Verano Los capuchinos y la Divina Pastora (pp. 101130). Córdoba: CajaSur.

Rodríguez de Tembleque García, S. E. (2014). La hermandad de la Misericordia para pobres enfermos del Perchel y el beato Diego José de Cádiz, La Saeta de Otoño 54, 99-105.

--- (2016). Ecdótica y estudio lingüístico de los villancicos del siglo XVIII del Archivo de la Catedral de Málaga. (Tesis doctoral). Málaga: Universidad. Recuperado de https://riuma.uma.es/xmlui/handle/10630/13828 
Sánchez López, J. A. (1996). Iconografía dieciochesca en Málaga: Interpretaciones escultóricas del tema de la Divina Pastora, Baética: Estudios de arte, geografía e historia 18, 3761.

Ubrique, S. de (1926). Vida del Beato José de Cádiz, Misionero Apostólico Capuchino. Tomos I y II. Sevilla: Imprenta de la Divina Pastora.

Valencina, A. de (1902). El director perfecto y el dirigido santo: correspondencia epistolar del B. Diego José de Cádiz con el V. P. Maestro Francisco Javier González y viceversa. Sacada a la luz y anotada por el P. Ambrosio de Valencina. Sevilla: Imprenta de la Divina Pastora. 